\title{
Ageing, chronic alcohol consumption and folate are determinants of genomic DNA methylation, $p 16$ promoter methylation and the expression of $p 16$ in the mouse colon
}

\author{
Julia Sauer ${ }^{1}$, Hyeran Jang ${ }^{1}$, Ella M. Zimmerly ${ }^{1}$, Kyong-chol Kim ${ }^{1,2}$, Zhenhua Liu ${ }^{1}$, Aurelie Chanson ${ }^{1}$, \\ Donald E. Smith ${ }^{3}$, Joel B. Mason ${ }^{1}$, Simonetta Friso ${ }^{4}$ and Sang-Woon Choi ${ }^{1 *}$ \\ ${ }^{1}$ Vitamins and Carcinogenesis Laboratory, Jean Mayer USDA Human Nutrition Research Center on Aging, Tufts University, \\ Boston, MA, USA \\ ${ }^{2}$ Department of Family Medicine, Mizmedi Hospital, Seoul, Korea \\ ${ }^{3}$ Comparative Biology Unit, Jean Mayer USDA Human Nutrition Research Center on Aging, Tufts University, Boston, MA, USA \\ ${ }^{4}$ University of Verona School of Medicine, Verona, Italy \\ (Received 18 August 2009 - Revised 8 December 2009 - Accepted 4 January 2010 - First published online 8 March 2010)
}

Older age, dietary folate and chronic alcohol consumption are important risk factors for the development of colon cancer. The present study examined the effects of ageing, folate and alcohol on genomic and p16-specific DNA methylation, and p16 expression in the murine colon. Old (aged 18 months; $n$ 70) and young (aged 4 months; $n$ 70) male C57BL/6 mice were pair-fed either a Lieber-DeCarli liquid diet with alcohol (18\% of energy), a Lieber-DeCarli diet with alcohol (18\%) and reduced folate $(0.25 \mathrm{mg}$ folate $/ \mathrm{l})$ or an isoenergetic control diet $(0.5 \mathrm{mg}$ folate $/ \mathrm{l})$ for 5 or 10 weeks. Genomic DNA methylation, p16 promoter methylation and p16 gene expression were analysed by liquid chromatography-MS, methylation-specific PCR and real-time RT-PCR, respectively. Genomic DNA methylation was lower in the colon of old mice compared with young mice $(P<0.02)$ at 10 weeks. Alcohol consumption did not alter genomic DNA methylation in the old mouse colon, whereas it tended to decrease genomic DNA methylation in young mice $(P=0.08)$. p16 Promoter methylation and expression were higher in the old mouse colon compared with the corresponding young groups. There was a positive correlation between $p 16$ promoter methylation and $p 16$ expression in the old mouse colon $(P<0.02)$. In young mice the combination of alcohol and reduced dietary folate led to significantly decreased $p 16$ expression compared with the control group $(P<0 \cdot 02)$. In conclusion, ageing and chronic alcohol consumption alter genomic DNA methylation, p16 promoter methylation and p16 gene expression in the mouse colon, and dietary folate availability can further modify the relationship with alcohol in the young mouse.

Alcohol: DNA methylation: p16: Folate: Ageing: Colon

Diet has a fundamental role as an environmental factor in determining the risk of colorectal carcinogenesis; for example, diets high in animal fat or red meat and low in fruits and vegetables tend to increase its risk $^{(1-3)}$. Additionally, both epidemiological studies ${ }^{(4,5)}$ and animal experiments ${ }^{(6)}$ indicate that excessive alcohol intake plays an important contributory role in several common cancers, including those of the upper aerodigestive tract, liver, colorectum and breast ${ }^{(7,8)}$.

In laboratory animals, chronic alcohol consumption has been observed to decrease genomic DNA methylation in colonic tissue, apparently by diminishing the availability of the proximate methyl donor, S-adenosylmethionine. It is thought that this effect is due to the increased utilisation of one-carbon donors and through its antagonistic effect on folate metabolism, especially the enzyme methionine synthase $^{(9,10)}$. Folate is an essential cofactor in the synthesis of S-adenosylmethionine, the primary methyl donor for biological methylation. Since aberrations in DNA methylation (i.e. genomic DNA hypomethylation and gene-specific promoter hypermethylation) are an exceedingly common phenomenon in colorectal neoplasia ${ }^{(11,12)}$, alcohol-mediated inhibition of methyl transfer reactions may be an important mechanistic avenue for alcohol-related cancers ${ }^{(8)}$. DNA methylation of the promoter region is an important mechanism for the control of gene expression: in many but not all instances hypermethylation represses and hypomethylation activates gene expression. Interestingly, neoplastic cells invariably demonstrate genomic hypomethylation of DNA and often demonstrate promoter hypermethylation of critical genes, such as tumour-suppressor genes ${ }^{(13,14)}$. Thus, activation of oncogenes by hypomethylation and the silencing of cancerprotective genes by hypermethylation may present a pivotal step in cellular malignant transformation.

Normally, tissue-specific methylation patterns established during embryonic development are highly preserved ${ }^{(15)}$, but ageing and nutritional factors may modify these patterns ${ }^{(16,17)}$. 
It has been speculated that these age-related changes in methylation may contribute to the cellular hyperproliferation that occurs with ageing in some tissues, thereby promoting age-related diseases such as certain cancers ${ }^{(18,19)}$. Moreover, it has been shown that alcohol also modulates the methylation pattern of histones in conjunction with altered gene expression, and therefore altered methylation of molecules other than DNA may also be involved ${ }^{(20)}$. Like alcohol, ageing seems to promote genomic hypomethylation of DNA: rodent studies have observed this phenomenon in many organs, including the intestinal mucosa ${ }^{(21,22)}$. Moreover, ageing has also been observed to be associated with promoter hypermethylation of certain genes and repression of their expression in tissues such as the colon ${ }^{(23)}$.

The p16 protein plays an important role in the regulation of the cell cycle, retarding proliferation. Loss of $p 16$ function by promoter methylation is a common epigenetic phenomenon in human colorectal carcinogenesis ${ }^{(24)}$. Moreover, the expression of the gene, which generally increases with ageing ${ }^{(21,25)}$, is thought to play a mechanistic role in the ageing process because it promotes cell senescence and age-related decline in the functions of some organs ${ }^{(26)}$.

The central role of 5-methyltetrahydrofolate in methyl transfer, and thereby in DNA methylation, might explain the relationship between folate status and the risk of colon cancer $^{(14)}$. As explained above, ageing also induces genomic DNA hypomethylation and since rodent studies suggest that ageing directly impairs folate metabolism in the colon ${ }^{(27)}$, it has been proposed that ageing might contribute to colonic carcinogenesis in part through its inhibition of folate metabolism $^{(28)}$. Thus, we hypothesised that ageing, alcohol consumption and low dietary folate synergistically modify DNA methylation and the expression of the $p 16$ gene, both of which are highly associated with colonic carcinogenesis.

In the present study, we examined the impact of ageing and chronic alcohol consumption on select epigenetic features of DNA in the murine colon by measuring genomic DNA methylation, p16 promoter methylation and the expression of p16. We further examined how alcohol consumption and low dietary folate, representing two nutritional factors associated with carcinogenesis that are biochemically interconnected, modulate the effects of ageing on DNA methylation in the colon.

\section{Experimental methods}

\section{Animals and diets}

The present study was reviewed and approved by the Animal Care and Use Committee of the USDA Human Nutrition Research Center on Aging at Tufts University. Seventy male C57BL/6 mice (old mice; aged 18 months; weight 30.6 (SE 3.6) g) and seventy male C57BL/6 mice (young mice; aged 4 months; weight 27.0 (SE 2.3) g) were used in the present study. Mice were obtained from Charles River Laboratories (Wilmington, MA, USA). The older 18-month-old mice were aged 20 months old by the end of the study. All diets were obtained from Dyets, Inc. (Bethlehem, PA, USA). No sulfonamide antibiotics were used to suppress colonic folate production.
The mice in each of the two age groups were randomly assigned to three groups of either twenty-three or twentyfour animals each. After 1 week of adaptation to the L-amino acid defined Lieber-DeCarli liquid control diet, one group was fed an L-amino acid defined Lieber-DeCarli alcohol $\operatorname{diet}^{(29)}$. The folate concentration in the Lieber-DeCarli was $0.5 \mathrm{mg}$ folic acid/l liquid diet, which is equivalent to $2 \mathrm{mg}$ folic acid/kg dry diet and accepted as the basal requirement for the mouse. Ethanol was present at a concentration of $6.2 \%(\mathrm{v} / \mathrm{v})$, comprising $36 \%$ of total energy, and was gradually introduced over an adaptation period of 2 weeks. In week 1 , the animals in the alcohol groups were given $12 \%$ ethanol and in week 2 they were given $24 \%$ to reach $36 \%$ ethanol by the starting time point of the study. The second group received the same Lieber-DeCarli alcohol diet with folate depletion ( $0 \mathrm{mg}$ folic acid/l liquid diet), which was introduced following the same schedule. The third group of mice received isoenergetic Lieber-DeCarli liquid control diets with $0.5 \mathrm{mg}$ folic acid/1 with an isoenergetic amount of maltodextrin. Water was not provided because the liquid diets provided enough fluid.

Individually housed mice were group pair-fed to decrease variability of energy and nutrient intake within and between dietary groups. The amount of food supplied to each diet group was matched to the mean daily food consumption of the group within the age category with the least food consumption. Therefore, all mice in each age group were offered the same volume of liquid daily and adjusted when necessary to ensure that all mice consumed equal volumes. All diets contained $16.11 \%$ of energy as amino acids and $33.75 \%$ of energy as fat. In the control diet, $47.7 \%$ of the energy was derived from carbohydrates; in the alcohol diet this value was $11.7 \%$. We confirmed the concentration of $0.5 \mathrm{mg}$ folate $/ \mathrm{l}$ in the liquid diets with the microbiological assay. No folate was detectable in the folate-depleted diet.

Within the first week after completion of the adaptation period some of the old mice receiving $36 \%$ ethanol started to die. Eight mice in the $36 \%$ ethanol group and seven in the $36 \%$ ethanol with folate depletion group died. No animals from the control group died. To prevent further loss during the study the ethanol concentration was reduced to $18 \%$ by mixing equal portions of the ethanol and control diets, yielding an alcohol diet that was isoenergetic with the control diet. Due to inclusion of the control diet, the $18 \%$ ethanol diet with folate depletion was enriched with folate $(0 \cdot 25 \mathrm{mg} / \mathrm{l})$. Young mice were also fed the same alcohol diets. At 5 and 10 weeks, mice were killed and colon samples were harvested as previously described ${ }^{(27)}$.

\section{Hepatic folate concentration}

Folate concentrations in liver and diets were measured by a conventional microbiological microtitre plate assay using Lactobacillus casei $^{(30)}$. Due to the limited amount of colonic mucosal scrapings, we measured hepatic folate levels to determine systemic folate status.

\section{Real-time RT-PCR assay for p16 gene expression}

The expression of p16 on transcriptional level was quantified using a Taqman Gene Expression Assay and an ABI Prism 
7300 Sequence Detection system (Applied Biosystems, Foster City, CA, USA). Statistical analyses were performed using $\Delta \mathrm{Ct}$ (cycle threshold) after normalising gene expression to glyceraldehyde 3-phosphate dehydrogenase (GAPDH) $\left(\Delta \mathrm{Ct}=\mathrm{Ct}_{\mathrm{p} 16}-\mathrm{Ct}_{\mathrm{GAPDH}}\right)$. Thus, lower $\Delta \mathrm{Ct}$ values indicate greater $p 16$ gene expression.

\section{Genomic and $\mathrm{p} 16$ promoter DNA methylation}

DNA methylation was measured using liquid chromatography electrospray ionisation mass spectrometry as described ${ }^{(31)}$. DNA methylation of the $p 16$ promoter region was determined by bisulfite modification of genomic DNA and subsequent methylation-specific PCR, as described in detail elsewhere ${ }^{(21,32,33)}$. Briefly, $1 \mu \mathrm{g}$ genomic DNA was bisulfite treated, desulfonated and recovered using a column-based kit (EZ DNA Methylation Gold; Zymo Research, Orange, CA, USA). Subsequently, DNA was amplified with a methyl-specific primer set ( $\mathrm{M}$ forward, CGATTGGGCGGGTATTGAATTTTCGC; $\mathrm{M}$ reverse, CACGTCATACACACGACCCTAAACCG) and an unmethyl-specific primer set (U forward, GTGATTGGGTGGGTATTGAATTTTTGTG; U reverse, CACACATCATACACACAACCCTAAACCA) for the mouse p16 promoter site ${ }^{(33)}$. Methyl amplification conditions included an initial denaturation at $95^{\circ} \mathrm{C}$ for $10 \mathrm{~min}$, denaturation at $94^{\circ} \mathrm{C}$ for $30 \mathrm{~s}$, annealing at $66^{\circ} \mathrm{C}$ for $1 \mathrm{~min}$, and extension at $72^{\circ} \mathrm{C}$ for $1 \mathrm{~min}$ for forty cycles, followed by stabilisation for $8 \mathrm{~min}$ at $72^{\circ} \mathrm{C}$. Unmethyl amplification followed the same procedure but with an annealing temperature of $64^{\circ} \mathrm{C}$. The PCR products were separated by gel electrophoresis and stained with SYBR. The volume (intensity $\times \mathrm{mm}^{2}$ ) of methyl and unmethyl PCR products was quantified under UV light and promoter methylation status was relatively quantified as percentage of methyl band/(methyl band + unmethyl band $)^{(34)}$.

\section{Statistics}

To determine statistically significant differences between the age and diet groups at each time point, two-way ANOVA followed by Tukey's post hoc analysis was applied to determine the locations and level of significance. Logarithmic transformation was performed on skewed variables to

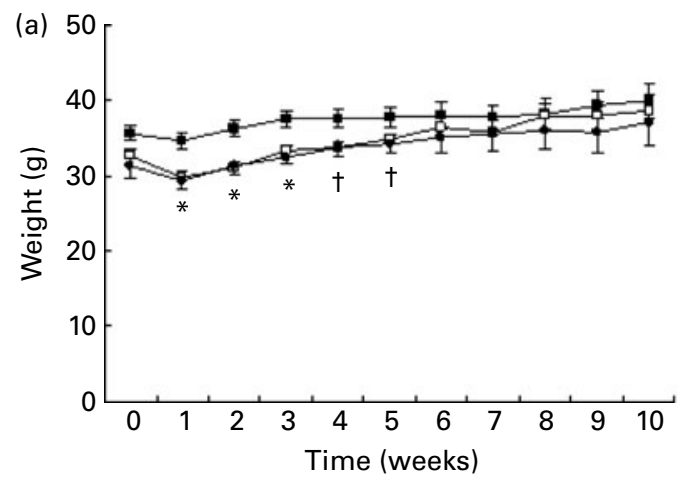

normalise their distributions and statistical comparison was carried out on log-transformed data. The level of significance was $P<0.05$ for all analyses. Values are presented as mean values with their standard errors.

\section{Results}

Animals

The body weights of old mice fed the control liquid diet remained stable throughout the experiment (Fig. 1). Initially, old mice fed the $18 \%$ alcohol diets lost weight in week 1 but thereafter started to gain weight, and by 6 weeks there were no significant differences between the weights of the three groups of old mice. Despite the weight difference, all mice tolerated the liquid diets very well. During the 10 -week experimental period two old mice in the control group died.

Young mice fed the control diet gained weight progressively during the experimental period. Like the older mice, young mice on the $18 \%$ alcohol diets lost weight in week 1, but thereafter started to gain weight. This effect was observed in both the $18 \%$ alcohol diet and the $18 \%$ alcohol diet with reduced folate. By the end of the study, there remained a significant weight difference between the mice fed alcoholcontaining diets and the control mice (Fig. 1). Among the young mice, one mouse died in the $18 \%$ alcohol group and two mice died in the $18 \%$ alcohol with reduced folate group before the end of the study. Necropsy of the mice that died early did not reveal any specific abnormality or disease.

\section{Hepatic folate concentration}

The mean hepatic folate concentrations (Table 1) were lower in old mice compared with young mice (10.4 (SEM 0.3) v. 11.5 (SEM 0.3) $\mu \mathrm{g} / \mathrm{g}$ tissue; $P<0.02$ ). Moreover, at 10 weeks the alcohol-fed old mice had a tendency of higher mean hepatic folate concentration compared with control old mice (11.4 (SEM 0.5) v. 9.3 (SEM 0.4) $\mu \mathrm{g} / \mathrm{g}$ tissue; $P=0.08$ ). Interestingly, the alcohol diet with reduced folate showed the same level of folate as the control. Hepatic folate concentrations did not differ among young mice groups.

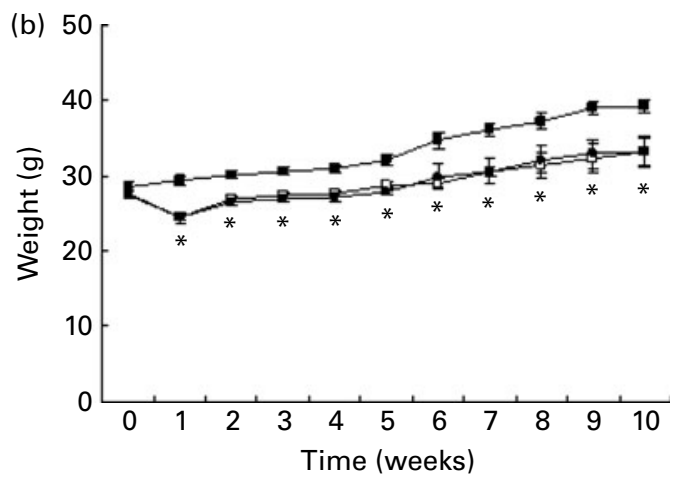

Fig. 1. Body weights in old (a) and young (b) male C57BL/6 mice fed a control diet (-- -), an $18 \%$ ethanol diet (- $\square-$ ) or an $18 \%$ ethanol + folate-depleted diet $(-\bullet-)$. Values are means ( $n$ 15-24 for the first 5 weeks; $n$ 8-13 for the second 5 weeks), with standard errors represented by vertical bars. ${ }^{*}$ Mean value was significantly different from those of mice fed both ethanol-containing diets $(P<0.05)$. † Mean value was significantly different from that of mice fed the $18 \%$ ethanol + folate-depleted diet $(P<0.05)$. 
Table 1. Liver folate concentrations ( $\mu \mathrm{g} / \mathrm{g}$ tissue) in old (aged 18 months) and young (aged 4 months) male C57BL/6 mice fed a control diet, an $18 \%$ ethanol-containing diet or an $18 \%$ ethanol + low-folate diet for 5 and 10 weeks $^{*}$

(Mean values with their standard errors)

\begin{tabular}{|c|c|c|c|c|c|c|c|c|c|c|c|c|}
\hline \multirow[b]{3}{*}{ Diet } & \multicolumn{6}{|c|}{ Old mice } & \multicolumn{6}{|c|}{ Young mice } \\
\hline & \multicolumn{3}{|c|}{5 weeks } & \multicolumn{3}{|c|}{10 weeks } & \multicolumn{3}{|c|}{5 weeks } & \multicolumn{3}{|c|}{10 weeks } \\
\hline & $n$ & Mean & SEM & $n$ & Mean & SEM & $n$ & Mean & SEM & $n$ & Mean & SEM \\
\hline Control & 11 & $10 \cdot 3$ & 0.8 & 11 & $9 \cdot 3$ & 0.4 & 10 & 11.9 & 1.2 & 13 & $11 \cdot 1$ & 0.4 \\
\hline $18 \%$ Ethanol & 7 & 11.5 & $1 \cdot 2$ & 8 & $11.4 \dagger$ & 0.5 & 10 & $12 \cdot 3$ & 0.7 & 12 & 11.0 & 0.5 \\
\hline $18 \%$ Ethanol + low folate & 8 & $10 \cdot 9$ & 0.4 & 9 & 9.7 & 0.8 & 10 & $11 \cdot 8$ & 1.6 & 12 & 11.5 & 0.5 \\
\hline
\end{tabular}

\section{Genomic DNA methylation of the colon}

Overall, genomic DNA methylation of the colonic mucosa was significantly lower in old mice compared with young mice by the end of the experiment (4.43 (SEM 0.04) v. 4.58 (SEM 0.04$) \% ; P<0.02$ ). This was also evident by the end of the experiment among the mice fed control diets: old mice fed the control diet showed a decreased colonic DNA methylation compared with that of young mice fed the same control diet $(P<0.02)$. The presence of alcohol blunted the difference in methylation between the young and old: at 5 weeks the old mice fed alcohol with reduced dietary folate had a tendency of lower mean DNA methylation compared with the corresponding young mice $(P=0.08)$. Also, at 10 weeks young mice fed alcohol demonstrated a tendency to have lower genomic DNA methylation compared with young control mice $(P=0.08)$ (Table 2$)$.

\section{p16 Promoter methylation and p16 expression}

Old mice had a dramatically greater degree of $p 16$ promoter methylation in all three diet groups at both 5 and 10 weeks $(P<0.001)$ compared with the corresponding young groups, since young mice demonstrated low methylation status regardless of their diet. Neither alcohol consumption nor alcohol consumption with reduced dietary folate affected $p 16$ promoter methylation in either of the age groups (Fig. 2).

All old mice groups showed an increased p16 expression compared with corresponding young mice groups $(P<0.05)$ except alcohol-fed groups at 5 weeks (Table 3). Although there was no difference in pl6 gene expression among the three diet groups in old mice, young mice fed alcohol with reduced folate had decreased p16 expression compared with the control group at both $5(P<0.02)$ and 10 weeks $(P<0 \cdot 01)$. In contrast, young mice fed alcohol, but with sufficient folate, did not have significantly lower $p 16$ expression compared with control mice.

Interestingly, there is a positive correlation between $p 16$ expression and promoter methylation in the colon of old mice (Fig. 3; $P<0.02$ ) whereas in the young mice, among which colon p16 promoter methylation status was invariably low, no significant relationship was observed.

\section{Discussion}

In the present study we used an older mouse model to examine whether genomic and $p 16$ gene-specific DNA methylation and p16 gene expression, all of which are relevant to carcinogenesis, are modified by factors that are thought to have an impact on colorectal cancer risk: alcohol ingestion, dietary folate and ageing. Overall, we observed that older age has a remarkably robust and consistent impact on these molecular endpoints, whereas the effects of alcohol and mild folate depletion were more subtle and complex.

Ageing had a prominent role in determining genomic DNA methylation. Our present observations confirm a prior study of ours in which we demonstrated that genomic DNA methylation of the murine colon decreases with ageing ${ }^{(21)}$, and this

Table 2. Genomic DNA methylation of colonic mucosa (\% methylation) in old and young mice fed a control diet, an $18 \%$ ethanol-containing diet and an $18 \%$ ethanol + low-folate diet for 5 and 10 weeks*

(Mean values with their standard errors)

\begin{tabular}{|c|c|c|c|c|c|c|c|c|c|c|c|c|}
\hline \multirow[b]{3}{*}{ Diet } & \multicolumn{6}{|c|}{ Old mice } & \multicolumn{6}{|c|}{ Young mice } \\
\hline & \multicolumn{3}{|c|}{5 weeks } & \multicolumn{3}{|c|}{10 weeks } & \multicolumn{3}{|c|}{5 weeks } & \multicolumn{3}{|c|}{10 weeks } \\
\hline & $n$ & Mean & SEM & $n$ & Mean & SEM & $n$ & Mean & SEM & $n$ & Mean & SEM \\
\hline Control & 11 & 4.58 & 0.06 & 11 & $4.37 \dagger$ & 0.08 & 10 & $4 \cdot 37$ & 0.15 & 13 & 4.75 & 0.08 \\
\hline $18 \%$ Ethanol & 7 & 4.52 & 0.06 & 8 & 4.60 & 0.06 & 10 & 4.67 & 0.07 & 12 & $4.44 \S$ & $0 \cdot 10$ \\
\hline $18 \%$ Ethanol + low folate & 8 & $4 \cdot 22 \ddagger$ & 0.12 & 9 & $4 \cdot 31$ & 0.11 & 10 & 4.61 & 0.09 & 12 & 4.63 & 0.07 \\
\hline
\end{tabular}

* DNA methylation in all old mice was significantly lower than that of all young mice (4.43 (SEM 0.04) v. 4.58 (SEM 0.04) \%; $P<0.02)$

$\dagger$ Mean value was significantly different from that of the corresponding young mice $(P<0.02)$.

$\ddagger$ Mean value tended to be significantly different from that of the corresponding young mice $(P=0.08)$.

$\S$ Mean value tended to be significantly different from that of the young control mice $(P=0.08)$. 
(a)

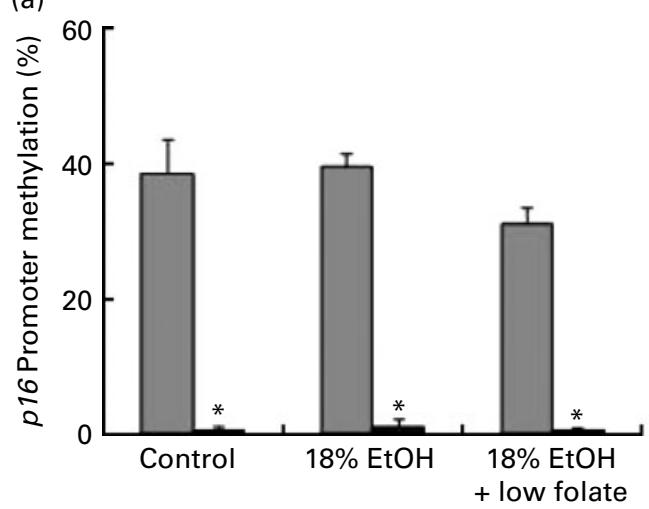

(b)

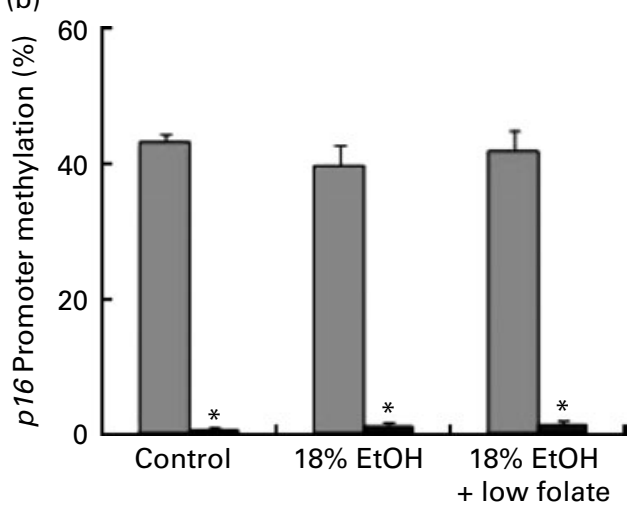

Fig. 2. Promoter methylation of $p 16$ in the colon of old (18 months; $\square$ ) and young (4 months; $\square$ ) mice fed a control, an $18 \%$ ethanol-containing diet (18\% EtOH) or an $18 \%$ ethanol + low-folate diet (18\% EtOH + low folate) for 5 (a) and 10 weeks (b). Values are means, with standard errors represented by vertical bars. ${ }^{*}$ Mean value was significantly different from that of the old mice $(P<0.001)$.

age-related decline in genomic methylation of the colon appears to follow the same pattern in human subjects ${ }^{(35)}$. At 10 weeks, DNA methylation was significantly lower in all old mice compared with all young mice $(P<0 \cdot 02)$.

Young mice fed alcohol demonstrated a tendency to have lower genomic DNA methylation compared with young control mice at 10 weeks. This observation is consistent with our previous study using young rats in which we found decreased genomic DNA methylation in the colon after 4 weeks of alcohol consumption ${ }^{(36)}$. Even though alcohol did not change genomic methylation in the old mice colon, it attenuated the ability to discern an effect of age on genomic methylation. The weak effect of alcohol on genomic DNA methylation, especially for the aged mice, may be related to alcohol exposure time that might be too short to affect genomic DNA methylation but more probably is related to the fact that alcohol was administered as $18 \%$ of total energy, which is a much lower concentration of alcohol compared with $36 \%$ of total energy that had been used in the former rat study ${ }^{(36)}$.

Interestingly, the alcohol diet had a tendency to increase hepatic folate concentrations in old mice, which is consistent with what was observed in some prior rodent studies ${ }^{(36-38)}$. The observed increase in hepatic folate level might be related to the development of a methyl-folate trap, in which the methylated form of folate is accumulated in tissue and less utilised due to the inhibition of alcohol on methionine synthase $^{(39)}$. Interestingly, at 5 weeks the old mice fed alcohol with reduced dietary folate had a tendency of lower mean DNA methylation compared with the corresponding young mice. It seems that they did not reach the significant level due to the mild degree of folate depletion in the diet. Since old mice also had lower overall hepatic folate concentrations compared with young mice $(P<0.02)$, diets may more influence folate level in old mice and reduced dietary folate decreased DNA methylation in old mice along with the methyl-folate trap induced by alcohol.

Gene-specific promoter hypermethylation appears to be an important biomarker of several human neoplasms, including colorectal cancer ${ }^{(40)}$. The $p 16$ gene product has a central function in controlling the cell cycle. Our observations indicate that promoter methylation of $p 16$ was not modified by chronic alcohol consumption for 10 weeks, regardless of if mild folate depletion was also present. On the other hand we found a prominent ageing effect on $p 16$ promoter methylation, which is consistent with a previous study of the older mouse colon $^{(21)}$, and which is a phenomenon that has been described in the older human colon as well ${ }^{(41)}$. Compared with ageing, a relatively short period of reduced methyl availability by alcohol consumption and reduced dietary folate might not be sufficient to perturb the system.

The hypothesis that hypermethylation of the $p 16$ promoter can diminish its expression in colonic carcinogenesis ${ }^{(42)}$ does not appear in the older normal colon, because there is a significant increase in $p 16$ expression that parallels increases

Table 3. $p 16$ Expression $(\Delta \mathrm{Ct})$ in colonic mucosa of old (18 months) and young (4 months) mice fed a control diet, an $18 \%$ ethanolcontaining diet and an $18 \%$ ethanol + low-folate diet for 5 and 10 weeks

(Mean values with their standard errors)

\begin{tabular}{|c|c|c|c|c|c|c|c|c|c|c|c|c|}
\hline \multirow[b]{3}{*}{ Diet } & \multicolumn{6}{|c|}{ Old mice } & \multicolumn{6}{|c|}{ Young mice } \\
\hline & \multicolumn{3}{|c|}{5 weeks } & \multicolumn{3}{|c|}{10 weeks } & \multicolumn{3}{|c|}{5 weeks } & \multicolumn{3}{|c|}{10 weeks } \\
\hline & $n$ & Mean & SEM & $n$ & Mean & SEM & $n$ & Mean & SEM & $n$ & Mean & SEM \\
\hline Control & 11 & $17 \cdot 2^{*}$ & 0.4 & 11 & $16 \cdot 4^{\star}$ & 0.3 & 10 & $19 \cdot 2^{\mathrm{a}}$ & 0.2 & 13 & $18 \cdot 7^{\mathrm{a}}$ & 0.3 \\
\hline $18 \%$ Ethanol & 7 & 18.4 & 0.5 & 8 & $16 \cdot 5^{*}$ & 0.5 & 10 & $19 \cdot 3^{a, b}$ & 0.3 & 12 & $19 \cdot 3^{\mathrm{a}}$ & 0.3 \\
\hline $18 \%$ Ethanol + low folate & 8 & $17 \cdot 3^{*}$ & 0.3 & 9 & $17 \cdot 0^{*}$ & 0.3 & 10 & $20 \cdot 8^{c}$ & 0.4 & 12 & $20 \cdot 5^{\mathrm{b}}$ & 0.4 \\
\hline
\end{tabular}

a,b,c Mean values within a column with unlike superscript letters were significantly different $(P<0.05)$.

* Mean value was significantly different from that of young mice in the corresponding dietary group $(P<0.05)$. 


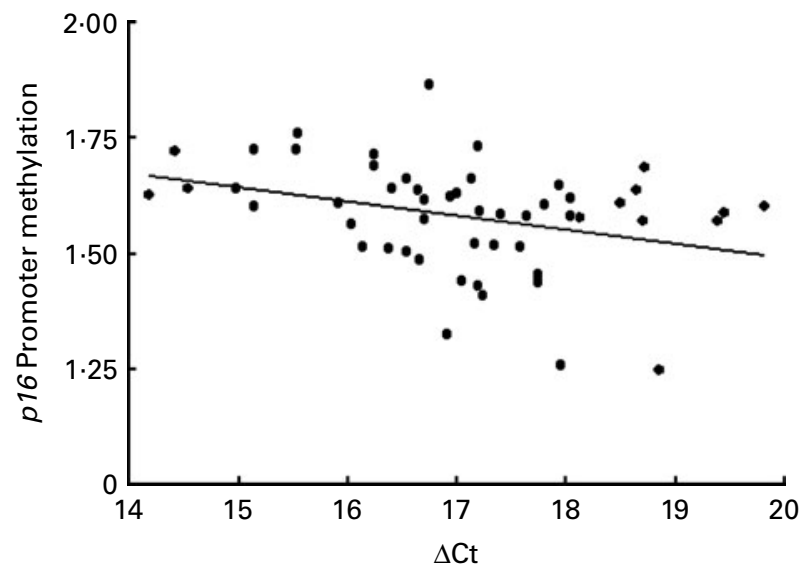

Fig. 3. Correlation $(P<0.02)$ between $p 16$ expression status ( $\Delta \mathrm{Ct}$ values) and promoter methylation (log-transformed) in the colon of old mice.

in promoter methylation in the old mice. Promoter methylation affects gene expression in conjunction with a number of other regulatory factors, such as histone modifications, methyl binding proteins and transcription factors, and therefore further studies will be required to explain the regulation of p16 expression in the normal colon. In contrast, young mice had invariably low promoter methylation status and markedly lower p16 expression, as was seen in our prior study ${ }^{(21)}$. In addition, the combination of alcohol and reduced dietary folate significantly diminished the gene's expression, an effect not seen with alcohol alone, demonstrating a synergy between alcohol and low dietary folate. This latter effect on p16 expression is apparently conveyed by mechanisms other than promoter methylation.

Minor differences in weight gain due to alcohol administration feasibly introduced some confounding, although we believe that the effects were minimal. Both young and old mice that were fed alcohol gained less weight than mice fed the control diets during the 10 weeks of the study. This difference in the animal weights was expected ${ }^{(43)}$ and has been previously ascribed to the different metabolic fates of nutrients that can be utilised as an energy source ${ }^{(44)}$. Old, but not young, mice that were fed alcohol caught up with the weight gain of their non-alcohol controls towards the latter half of the study, suggesting that old mice are better able to utilise energy from alcohol than the young. Perhaps the high metabolic demands for growth and development make the younger adult more vulnerable in this regard.

In conclusion, our observations indicate that older age is a major determinant of p16 methylation and expression in the colon of the mouse and p16 promoter methylation and expression are positively associated in the aged colon. Chronic alcohol consumption, which interferes with biological methylation, tended to reduce genomic DNA methylation in the colon of young mice, and the combination of alcohol and reduced dietary folate played minor roles in the colon of old mice. Young mice fed alcohol with reduced folate had decreased p16 expression, indicating that dietary folate availability can further modify the relationship with alcohol in the young mouse. Our observations also underscore the idea that promoter methylation is not invariably the main factor determining pl6 expression by ageing and chronic alcohol consumption in non-neoplastic colon, even though promoter hypermethylation of p16 is thought to play a role in the evolution of neoplasia in the colon by suppressing expression of the gene.

\section{Acknowledgements}

This material is based upon work supported by the United States Department of Agriculture, under agreement no. 581950-9-001. Any opinions, findings, conclusion, or recommendations expressed in this publication are those of the author(s) and do not necessarily reflect the view of the United States Department of Agriculture.

This project has been supported in part by the National Institutes of Health grants R21 AA016681 and R01 AG025834 (to S.-W. C.) and the National Institutes of Health grants U54 CA10097 and K05 CA100048 (to J. B. M.).

All authors participated in the conception, design and performance of the study as well as interpretation of data and drafting the manuscript. J. S., H. J. and S.-W. C. also performed the generation, collection and analysis of data.

The authors do not have any competing interest.

\section{References}

1. Cummings JH \& Bingham SA (1998) Diet and the prevention of cancer. BMJ 317, 1636-1640.

2. Norat T, Bingham S, Ferrari P, et al. (2005) Meat, fish, and colorectal cancer risk: the European Prospective Investigation into Cancer and Nutrition. J Natl Cancer Inst 97, 906-916.

3. Riboli E \& Norat T (2003) Epidemiologic evidence of the protective effect of fruit and vegetables on cancer risk. Am J Clin Nutr 78, Suppl. 3, 559S-569S.

4. Brown LM (2005) Epidemiology of alcohol-associated cancers. Alcohol 35, 161-168.

5. Morgan TR, Mandayam S \& Jamal MM (2004) Alcohol and hepatocellular carcinoma. Gastroenterology 127, Suppl. 1, S87-S96.

6. Roy HK, Gulizia JM, Karolski WJ, et al. (2002) Ethanol promotes intestinal tumorigenesis in the MIN mouse multiple intestinal neoplasia. Cancer Epidemiol Biomarkers Prev 11, 1499-1502.

7. Seitz HK, Maurer B \& Stickel F (2005) Alcohol consumption and cancer of the gastrointestinal tract. Dig Dis 23, 297-303.

8. Seitz HK \& Stickel F (2007) Molecular mechanisms of alcoholmediated carcinogenesis. Nat Rev Cancer 7, 599-612.

9. Lu SC, Huang ZZ, Yang H, et al. (2000) Changes in methionine adenosyltransferase and S-adenosylmethionine homeostasis in alcoholic rat liver. Am J Physiol Gastrointest Liver Physiol 279, G178-G185.

10. Schalinske KL \& Nieman KM (2005) Disruption of methyl group metabolism by ethanol. Nutr Rev 63, 387-391.

11. Feinberg AP, Gehrke CW, Kuo KC, et al. (1988) Reduced genomic 5-methylcytosine content in human colonic neoplasia. Cancer Res 48, 1159-1161.

12. Guerrero-Preston R, Santella RM, Blanco A, et al. (2007) Global DNA hypomethylation in liver cancer cases and controls: a phase I preclinical biomarker development study. Epigenetics 2, 223-226.

13. Goelz SE, Vogelstein B, Hamilton SR, et al. (1985) Hypomethylation of DNA from benign and malignant human colon neoplasms. Science 228, 187-190.

14. Choi SW \& Mason JB (2000) Folate and carcinogenesis: an integrated scheme. J Nutr 130, 129-132. 
15. Razin A \& Shemer R (1995) DNA methylation in early development. Hum Mol Genet 4, 1751-1755.

16. Liu L, Wylie RC, Andrews LG, et al. (2003) Aging, cancer and nutrition: the DNA methylation connection. Mech Ageing Dev 124, 989-998.

17. Wilson VL, Smith RA, Ma S, et al. (1987) Genomic 5-methyldeoxycytidine decreases with age. $J$ Biol Chem 262, 9948-9951.

18. Catania J \& Fairweather DS (1991) DNA methylation and cellular ageing. Mutat Res 256, 283-293.

19. Gloria L, Cravo M, Pinto A, et al. (1996) DNA hypomethylation and proliferative activity are increased in the rectal mucosa of patients with long-standing ulcerative colitis. Cancer 78, $2300-2306$.

20. Shukla SD, Velazquez J, French SW, et al. (2008) Emerging role of epigenetics in the actions of alcohol. Alcohol Clin Exp Res 32, 1525-1534.

21. Keyes MK, Jang H, Mason JB, et al. (2007) Older age and dietary folate are determinants of genomic and $p 16$-specific DNA methylation in mouse colon. $J$ Nutr 137, 1713-1717.

22. Richardson B (2003) Impact of aging on DNA methylation. Ageing Res Rev 2, 245-261.

23. Issa JP (2000) CpG-island methylation in aging and cancer. Curr Top Microbiol Immunol 249, 101-118.

24. Esteller M, Corn PG, Baylin SB, et al. (2001) A gene hypermethylation profile of human cancer. Cancer Res 61, 3225-3229.

25. Collins CJ \& Sedivy JM (2003) Involvement of the INK4a/Arf gene locus in senescence. Aging Cell 2, 145-150.

26. Krishnamurthy J, Ramsey MR, Ligon KL, et al. (2006) p16INK4a induces an age-dependent decline in islet regenerative potential. Nature 443, 453-457.

27. Choi SW, Friso S, Dolnikowski GG, et al. (2003) Biochemical and molecular aberrations in the rat colon due to folate depletion are age-specific. J Nutr 133, 1206-1212.

28. Jang H, Mason JB \& Choi SW (2005) Genetic and epigenetic interactions between folate and aging in carcinogenesis. $J$ Nutr 135, Suppl. 12, 2967S-2971S.

29. Lieber CS, DeCarli LM \& Sorrell MF (1989) Experimental methods of ethanol administration. Hepatology 10, 501-510.

30. Tamura T (1990) Microbiological assay of folates. In Folic Acid Metabolism in Health and Diseases, pp. 121-137 [MF Picciano, ELR Stokstad and JF Gregory III, editors]. New York: Wiley-Liss.
31. Friso S, Choi SW, Dolnikowski GG, et al. (2002) A method to assess genomic DNA methylation using high-performance liquid chromatography/electrospray ionization mass spectrometry. Anal Chem 74, 4526-4531.

32. Herman JG, Graff JR, Myohanen S, et al. (1996) Methylationspecific PCR: a novel PCR assay for methylation status of CpG islands. Proc Natl Acad Sci U S A 93, 9821-9826.

33. Sharpless NE, Bardeesy N, Lee KH, et al. (2001) Loss of p16Ink4a with retention of p19Arf predisposes mice to tumorigenesis. Nature 413, 86-91.

34. Lo YM, Wong IH, Zhang J, et al. (1999) Quantitative analysis of aberrant p16 methylation using real-time quantitative methylation-specific polymerase chain reaction. Cancer Res 59, 3899-3903.

35. Suzuki K, Suzuki I, Leodolter A, et al. (2006) Global DNA demethylation in gastrointestinal cancer is age dependent and precedes genomic damage. Cancer Cell 9, 199-207.

36. Choi SW, Stickel F, Baik HW, et al. (1999) Chronic alcohol consumption induces genomic but not p53-specific DNA hypomethylation in rat colon. J Nutr 129, 1945-1950.

37. Wilkinson JA \& Shane B (1982) Folate metabolism in the ethanol-fed rat. J Nutr 112, 604-609.

38. Frank O \& Baker H (1980) Vitamin profile in rats fed stock or liquid ethanolic diets. Am J Clin Nutr 33, 221-226.

39. Mason JB \& Choi SW (2005) Effects of alcohol on folate metabolism: implications for carcinogenesis. Alcohol 35, $235-241$.

40. Herman JG, Merlo A, Mao L, et al. (1995) Inactivation of the CDKN2/p16/MTS1 gene is frequently associated with aberrant DNA methylation in all common human cancers. Cancer Res 55, 4525-4530.

41. Krakowczyk L, Strzelczyk JK, Adamek B, et al. (2008) Methylation of the MGMT and p16 genes in sporadic colorectal carcinoma and corresponding normal colonic mucosa. Med Sci Monit 14, BR219-BR225.

42. Kim BN, Yamamoto H, Ikeda K, et al. (2005) Methylation and expression of p16INK4 tumor suppressor gene in primary colorectal cancer tissues. Int J Oncol 26, 1217-1226.

43. Stickel F, Choi SW, Kim YI, et al. (2000) Effect of chronic alcohol consumption on total plasma homocysteine level in rats. Alcohol Clin Exp Res 24, 259-264.

44. Pirola RC \& Lieber CS (1972) The energy cost of the metabolism of drugs, including ethanol. Pharmacology 7, 185-196. 